\title{
Urological Aspects (Dynamic Bladder and Urethral Function, Urinary Tract Stones and Calcifications) in Patients with Alkaptonuria: A Case Control Study
}

Mohammed Suoub ( $\sim$ dr_suoub@yahoo.com)

Mu'tah University https://orcid.org/0000-0002-6736-0946

Mohammed Al-Sbou

Mu'tah University

Fadi Sawaqed

Mu'tah University

Research article

Keywords: alkaptonuria, urinary tract, stones, calcifications, bladder function, uroflowmetry

Posted Date: January 22nd, 2020

DOI: https://doi.org/10.21203/rs.2.21474/v1

License: (c) This work is licensed under a Creative Commons Attribution 4.0 International License.

Read Full License 


\section{Abstract}

Background The main objective of this study is to evaluate bladder, prostate and proximal urethral dynamic function and also to evaluate urinary tract stones and calcifications in patients with alkaptonuria.

Methods Thirty-eight patients were prospectively divided into two groups. Study group (A) involved 17 patients of an average age of 42 years (30-63 years). Control group (B) involved 21 patients of an average age of 37 years (31-62 years). All patients from the two groups underwent uroflowmetry assessment (peak flow rate, shape of the flow rate chart and voided volume) and ultrasonography for the kidneys and urinary bladder for two phases (full bladder and empty bladder). Finally, all patients had their prostate gland assessed in regard to calcification, prostatic stones and prostatic urethral stones.

Results Group A-Bladder volume ranged between 400 and $520 \mathrm{cc}$. The peak flow rate was between 7 and $23 \mathrm{ml} / \mathrm{sec}$, with an average of $18.6 \mathrm{ml} / \mathrm{sec}$. Flow rate curves shape were acceptable to normal bell shape curve in 11 patients. Seven patients $(41 \%)$ had prostate calcification of $5-35 \%$ of prostate size.Group B Bladder volume ranged between 290 and $510 \mathrm{cc}$. The peak flow rate was $8-27 \mathrm{cc} / \mathrm{sec}$ with an average of $20 \mathrm{ml} / \mathrm{sec}$. Normal bill shape voiding curves were observed in 17 patients $(80 \%)$. Four patients (19\%) had prostate calcification of $2-12 \%$ of prostate size. Renal measurements on ultrasonography were the same in both groups.

Conclusion Patients with Alkaptonuria had a slightly reduced peak urinary flow rate compared to the normal control group, but this was not statistically significant. The incidence of prostatic calcification was higher in alkaptonuria patients and they tended to develop prostate calcification at an earlier age than the control group. Regular urological assessment is recommended for all patients with alkaptonuria over the age of 30 years to detect early urological symptoms of the disease.

\section{Background:}

Alkaptonuria is one of four disorders originally defined by Archibald Garrod in his Croonian Lectures in 1902 (1) as an inborn error of metabolism. Alkaptonuria is a rare congenital disease. It is inherited in an autosomal recessive pattern $(2,3)$, with a $25 \%$ chance of disease in babies when both parents are affected, a $50 \%$ chance of being an asymptomatic carrier and a $25 \%$ chance of being unaffected and not a carrier (3). This metabolism disorder has a very low incidence (1 in 250,000), and is equally prevalent in females and males, with a higher morbidity and greater systemic effect observed in male patients. It has an earlier onset of arthritic symptoms with a greater degree of severity in males than in females.

It occurs due to an abnormality in metabolism of two amino acid-phenylalanine and tyrosine-pathways due to a deficiency in hepatic enzymes: homogentisate types 1 and 2 dioxygenase (4). These convert homogentesic acid (HGA) to maleylacetoacetic acid, which leads to the accumulation of HGA. HGA is an intermediate substance excreted through the kidney glomeruli with urine. Its effect in the urinary tract 
system begins in the renal glomeruli, and passes through the renal collection system to both uretersurinary bladder and urethra-through the prostate glade (prostatic urethra).

Patients are diagnosed with alkaptonuria if they have a higher concentration of HGA in their urine that turns urine to a black colour. If retained for a period of time, due to its oxidisation with air, a dark pigmentation (bluish to blackish) is observed in cartilage and connective tissue (ochronosis) $(5,6)$. Oxidisation of HGA leads to production of melanin-like polymers and inflammation of large joints and the spine, causing arthritis.

As alkaptonuria is a genetic disorder, homogentisate enzyme deficiency is present immediately after conception. However, most clinical symptoms usually present after the third decade of life. Dark-stained diapers, the only very early sign, are noticed immediately after affected babies start to pass urine.

Diagnosis of alkaptonuria is confirmed by gas chromatography-mass spectrometry analysis after identifying a significant amount of HGA in the urine (7). The amount of HGA excreted per day in individuals with alkaptonuria is usually $1-8$ grams.

Genetic evaluation and counselling in alkaptonuria patients can be conducted in the form of a carrier testing for at-risk relatives. Prenatal diagnosis for families at increased risk is possible if both HGA deficiency pathogenic variants in the family are known.

\section{Methods:}

From the Jordanian Alkaptonuria Society patient registry, which lists 70 patients with alkaptonuria, we accessed 23 patients. Patients voluntarily agreed be enrolled in this study and visit our clinic. Those patients were contacted via telephone and home visits.

Our three inclusions criteria for the study were male adult patients known to have alkaptonuria (whether on treatment or not). Six female patients with alkaptonuria were excluded from this study.

A prospective study on 38 patients was divided into two groups. Group A (the study group) involved 17 patients of an average age of 42 years (30-63 years). Group B (the control group) comprised 21 patients of an average age of 37 years (31-62 years). The control group matched to the ages of the members of the studied group, and members were randomly selected during a clinical visit for a medical condition unrelated to prostate or bladder disease. Urine cultures were conducted for all patients 72 hours prior to the study to exclude urinary tract infections. No patients had symptomatic urinary tract infection, fever or positive urine culture, and all were not on any medication related to prostate hyperplasia or bladder dynamic function.

All patients from the two groups underwent uroflowmetry (peak flow rate [PFR], shape of the flow rate chart and amount of voided urine) analysis using a flow rate machine (Life- Tech, module 1850UT). The normal flow curve was identified as smooth, unimodal and bell-shaped, with peak flow reached in the first 
$30 \%$ of trace and within 5 seconds (3-10 s) from the start of the flow. The normal range of male PFR is $15-25 \mathrm{ml} / \mathrm{sec}$.

Ultrasonography for all patients in the two groups was conducted to evaluate both kidneys for renal cortical thickness, renal stones, cortical calcification and hydronephrosis, urinary bladder for volume in two phases (full and empty) and prostate gland for size, calcification and prostatic urethra stones (using an ALOKA Prosound 2, model M00490 C ultrasound machine). Our reference range of normal bladder wall thickness was less than $4 \mathrm{~mm}$. Bladder residual urine after voiding is deemed normal if it is less than $20 \%$ of per-voided amount of urine. Prostate calcification was calculated according to the percent of calcification in relation to prostate size. First, the size of the prostate is measured; then calcification size is measured (if there is more than one calcification site, all sites are measured separately and added together) and divided over prostate size.

All patients in the two groups were asked to drink fluid over a period of two hours prior to the study to ensure that a good amount of urine was inside the bladder. Patients were asked to report any strong desire for urination to perform the tests. Ultrasonography and uroflowmetry were conducted in warm, comfortable conditions with maximum privacy to obtain a convenient result.

\section{Results:}

Uroflowmetry: In group A, total voided volume was $400-520 \mathrm{ml}$. PFR was 7-23 $\mathrm{ml} / \mathrm{sec}$ with an average of $18.6 \mathrm{ml} / \mathrm{sec}$. In this group, normal flow rate curve shape was observed in 11 patients; the other six patients had prolonged and extended PFR (see Table 1). In group B, total voided volume was 290$510 \mathrm{ml}$. PFR was 8-27 ml/sec, with an average of $20 \mathrm{ml} / \mathrm{sec}$. A normal flow curve was observed in 17 patients (80\%) (see Table 2).

Ultrasonography: In group A, normal bladder wall thickness was measured in 14 patients, while three patients $(21 \%)$ had bladder wall thickening of more than $4 \mathrm{~mm}$. No patient had bladder wall calcification, tumours or bladder stones. Sixteen patients $(94 \%)$ completely emptied their bladders with no significant residual urine, while only one patient $(6 \%)$ had a significant amount of urine remaining after voiding (post-void residual was $29 \%$ of pre-voided urine). In this particular patient, flowmetry curve was extended and prostate calcification was observed and measured at around 35\% (see Table 1). Seven patients (41\%) from group A had prostate calcification of $5-35 \%$ of prostate size, while the other 10 patients did not show any calcification in the prostate gland. Patients reported that they developed prostate calcification at an average age of 47 years (31-63 years). In group B in the full bladder phase, only two patients showed bladder wall thickening, but no masses or bladder wall calcification were observed in the control group. Only one patient had significant residual urine after voiding. The other 20 patients completely emptied their bladders. Prostate calcification was noticed in four patients (19\%)-the percentage of prostate calcification ranged between $2 \%$ and $15 \%$ of prostate size. Prostate calcification was detected at an average age of 57 years (52-62 years) (see Table 2). 
Assessment of renal size cortical thickness, cortico-medullary differentiation, was conducted. This is an indicator of renal function, as blood tests for serum creatinine and blood urea. This study did not conduct blood tests to assess renal function for the two groups. However, measurements on ultrasound of the two kidneys did not show any statistically significant difference between the two groups. This may indicate normal renal function. In the context of apparent renal cortical calcification, bladder volume ultrasonography did not reveal any significant differences between the two groups.

\section{Discussion:}

This study evaluated the dynamic function of urinary bladder and urethra, and bladder and prostatic calcification in patients with alkaptonuria. The study group was compared with an age-matched control group. All alkaptonuria patients were previously diagnosed with the disorder.

Dynamic bladder and prostatic urethral function have not evaluated before in alkaptonuria patients. As we know from literature reviews and the progress of the disease, patients may develop calcification in the prostate gland and sometimes in the bladder wall. These calcifications may affect bladder capacity and bladder contractility (dynamic function) and this effect may be detected in urine flow. Bladder capacity was normal in all evaluated alkaptonuria patients in this study in relation to the control group. Flow rate was slightly lower in alkaptonuria patients than in control group patients, but there was no statistically significant difference between the two groups. The number of patients and percent of prostate calcification were higher in alkaptonuria patients than in the control group. Increased prostate calcification may affect the flow of urine through the urethra, as the prostate gland represents the proximal part of the urethra (the urethra presses through the prostate gland via the transition zone). Calcification in the prostate gland may affect the elasticity of the proximal urethral (prostatic urethra), which may impair urinary flow through the prostate gland.

The literature review indicated that alkaptonuria patients have prostatic calcification, which may present as prostatic urethral stones (8) that may lead to bladder outflow obstruction and high pressure on the urinary bladder. This may result in bladder wall thickening to the point of bladder decompensation and bladder hypotonia. In this study, patients with alkaptonuria had a higher incidence of calcification in their prostate gland than those in the control group. However, this did not affect the flow of urine from the bladder enough to be considered statistically different from the control group.

There was only one article in the extant literature on prostatic stones and prostatic calcification compositions. The composition of the crystalline material present in five renal calculi and pieces of prostatic calculi from patients suffering from alkaptonuria was determined by the X-ray powder method. The urinary stones contain standard calculus constituents. Some pieces of the prostatic calculi comprise a substituted calcite $\mathrm{Ca}(\mathrm{Mg}, \mathrm{Mn}) \mathrm{CO}$, a substance not reported hitherto in a calculus. The stones, which are very dark in colour, also contain a small amount of the crystalline melanin-type oxidation product of HGA, and probably a larger amount of the pigment in a finely divided or amorphous state.(9) 
The general effects of alkaptonuria on the urinary tract begin in the kidneys and progress to the urethra. It may induce calcification and renal stones throughout the urinary tract; further, precipitation of some waste products inside renal glomeruli or renal tubules may result in renal damage and irreversible effects on the kidneys. The bladder and prostate gland may also be affected. Measurements of renal size, cortical thickness and cortico-medullary differentiation are good indicators of a normal renal function, in addition to blood investigations like serum creatinine, blood urea, urinalysis and microscopy. For financial reasons, we could not run those tests; this could be done in future research. In this study, ultrasound measurements for the two kidneys did not show any statistically significant difference between the two groups. This may indicate normal renal function, but laboratory results will contribute further information on kidney function.

The study showed greater prostatic calcification in the number of affected patients and percent of calcification in the prostate gland. However, this does not represent a statistically significant difference in bladder dynamic function from the control group. Patients with alkaptonuria developed prostate calcification earlier than those in the control group. Renal sizes and cortical thickness that reflected normal or abnormal kidney function were the same in both groups. In another prospective study, we may conduct renal function tests to assess renal function and compare it between alkaptonuria patients and the control group.

Limitations of this study were that some patients had been on medical treatment for alkaptonuria for 1.5 year, while others were not on any kind of medical treatment. Our patient group was not large enough to record a significant and valuable statistical different between the studied and control group due to the rarity of alkaptonuria. The study may be continued for a longer period of follow-up. Further, in addition to the control group, we may divide alkaptonuria patients into two group: treatment and no treatment. Adding a group of patients on alpha blocker medication with benign prostate hyperplasia may help determine if urinary flow rate improves in in alkaptonuria patients with prostate calcification.

\section{Conclusions:}

Patients with alkaptonuria had a slightly reduced peak urinary flow rate compared to the normal control group. They also had a greater incidence of prostatic calcification. Renal and bladder measurements were equal in both groups. Our recommendation is to perform urological assessment regularly for all patients with alkaptonuria above the age of 30 years.

\section{Declarations:}

List of Abbreviations: peak flow rate (PFR); homogentesic acid (HGA)

Ethics approval and consent to participate: The study was approved by the Institutional Ethical Committee at the Faculty of Medicine, Mutah University. Written informed consent was obtained from all 
participants upon their visit to the clinic.

Consent for publication: Not Applicable

Availability of data and materials: The datasets used and/or analysed during the current study are available from the corresponding author on reasonable request.

Competing Interests: The authors declare that they have no competing interests.

Funding: The study was not funded through any source.

Authors' Contributions: All authors have read and approved the manuscript. MS collected, analysed and interpreted patient data. MA shared the literature review and collected and interpreted patient data, FS analysed and interpreted patient data and was a major contributor in writing the manuscript.

Acknowledgement: The authors are very thankful to all associated personnel in any reference that contributed to the purpose of this research.

\section{References:}

1. Garrod AE. The incidence of alkaptonuria: a study in chemical individuality. 1902 [classical article]. Yale J Biol Med. 2002;75(4):221-31.

2. Al-Sbou M, Mwafi N, Lubad MA. Identification of forty cases with alkaptonuria in one village in Jordan. Rheumatol Int. 2012;32(12):3737-40.

3. Al-Sbou M, Mwafi N. Nine cases of Alkaptonuria in one family in southern Jordan. Rheumatol Int. 2012;32(3):621-5.

4. La Du BN, Zannoni VG, Laster L, Seegmiller JE. The nature of the defect in tyrosine metabolism in alcaptonuria. J Biol Chem. 1958;230(1):251-60.

5. Keller JM, Macaulay W, Nercessian OA, Jaffe IA. New developments in ochronosis: review of the literature. Rheumatol Int. 2005;25(2):81-5.

6. Fisher AA, Davis MW. Alkaptonuric ochronosis with aortic valve and joint replacements and femoral fracture: a case report and literature review. Clin Med Res. 2004;2(4):209-15.

7. Al-Sarayreh S, Tarawneh I, Alsbou M, Albataineh E, Al-Shuneigat J, Al-saraireh Y. Measurements of homogentisic acid levels in alkaptonuria patients using an optimized and validated gas chromatography method mass spectrometry. Jordan J Bio Sci. 2014;7.

8. Sutor DJ, Wooley SE, Křižzek V. The composition of calculi from patients with alcaptonuria. BJU Int. 1970;42(4):386-8

9. Fernandez-Canon JM, Granadino B, Beltran-Valero de Bernabe D, Renedo M, Fernandez-Ruiz E, Penalva MA, et al. The molecular basis of alkaptonuria. Nat Genet. 1996;14(1):19-24. 


\section{Tables}

Table 1: Age with uroflow rate, and bladder, prostate ultrasound in studied group (A) 17 Patients.

\begin{tabular}{ccccccccc}
\hline $\begin{array}{c}\text { Patient } \\
\#\end{array}$ & $\begin{array}{c}\text { Age } \\
\text { (Years) }\end{array}$ & $\begin{array}{c}\text { Peak } \\
\text { Flow } \\
\text { Rate } \\
\text { ml/sec }\end{array}$ & $\begin{array}{c}\text { Curve } \\
\text { Shape }\end{array}$ & $\begin{array}{c}\text { Pre-void } \\
\text { Urine } \\
\text { Volume } \\
\text { (ml) }\end{array}$ & $\begin{array}{c}\text { Residual } \\
\text { Urine } \\
\text { (\%) }\end{array}$ & $\begin{array}{c}\text { Voided } \\
\text { Volume } \\
\text { (ml) }\end{array}$ & $\begin{array}{c}\text { Percent of } \\
\text { Residual } \\
\text { Urine (\%) }\end{array}$ & $\begin{array}{c}\text { Prostate } \\
\text { Calcification (\% } \\
\text { to Prostate Size) }\end{array}$ \\
\hline 1 & 30 & 21 & Bill & 480 & 20 & 460 & $4 \%$ & 0 \\
2 & 30 & 19 & Bill & 450 & 10 & 440 & $2 \%$ & 0 \\
3 & 31 & 22 & Bill & 490 & 20 & 470 & $4 \%$ & $5 \%$ \\
4 & 32 & 23 & Bill & 400 & 10 & 390 & $2 \%$ & $5 \%$ \\
5 & 32 & 21 & Bill & 510 & 10 & 500 & $2 \%$ & 0 \\
6 & 33 & 21 & Bill & 480 & 20 & 460 & $4 \%$ & 0 \\
7 & 35 & 20 & Bill & 490 & 30 & 460 & $6 \%$ & 0 \\
8 & 41 & 16 & Extended & 440 & 50 & 390 & $11 \%$ & 0 \\
9 & 42 & 20 & Bill & 490 & 20 & 470 & $4 \%$ & 0 \\
10 & 42 & 18 & Bill & 490 & 10 & 480 & $2 \%$ & 0 \\
11 & 44 & 19 & Extended & 420 & 10 & 410 & $2 \%$ & $10 \%$ \\
12 & 44 & 18 & Extended & 440 & 50 & 390 & $11 \%$ & $10 \%$ \\
13 & 44 & 19 & Bill & 470 & 10 & 460 & $2 \%$ & 0 \\
14 & 48 & 21 & Bill & 520 & 40 & 480 & $7 \%$ & 0 \\
15 & 55 & 15 & Extended & 440 & 70 & 370 & $16 \%$ & $20 \%$ \\
16 & 60 & 16 & Extended & 430 & 50 & 380 & $12 \%$ & $20 \%$ \\
17 & 63 & 7 & Extended & 490 & 140 & 350 & $29 \%$ & $35 \%$ \\
\hline
\end{tabular}

Table 2: Age, urinary flow rate, and bladder, prostate ultrasound in control group (B) 21 Patients. 


\begin{tabular}{ccccccccc}
\hline $\begin{array}{c}\text { Patient } \\
\#\end{array}$ & $\begin{array}{c}\text { Age } \\
\text { (Years) }\end{array}$ & $\begin{array}{c}\text { Peak Flow } \\
\text { Rate } \\
\text { ml/sec }\end{array}$ & $\begin{array}{c}\text { Curve } \\
\text { Shape }\end{array}$ & $\begin{array}{c}\text { Pre-void } \\
\text { Urine } \\
\text { Volume } \\
\text { (ml) }\end{array}$ & $\begin{array}{c}\text { Residual } \\
\text { Urine } \\
(\%)\end{array}$ & $\begin{array}{c}\text { Voided } \\
\text { Volume } \\
(\mathrm{ml})\end{array}$ & $\begin{array}{c}\text { Percent of } \\
\text { Residual } \\
\text { Urine(\%) }\end{array}$ & $\begin{array}{c}\text { Prostate } \\
\text { Calcification (\% } \\
\text { to Prostate Size) }\end{array}$ \\
\hline 1 & 31 & 24 & Bill & 480 & 10 & 470 & $2 \%$ & 0 \\
2 & 31 & 25 & Bill & 510 & 30 & 480 & $6 \%$ & 0 \\
3 & 32 & 27 & Bill & 490 & 10 & 480 & $2 \%$ & 0 \\
4 & 33 & 23 & Bill & 510 & 20 & 490 & $4 \%$ & 0 \\
5 & 33 & 24 & Bill & 390 & 10 & 380 & $3 \%$ & 0 \\
6 & 35 & 23 & Bill & 480 & 35 & 445 & $8 \%$ & 0 \\
7 & 37 & 22 & bill & 470 & 20 & 450 & $4 \%$ & 0 \\
8 & 38 & 22 & Bill & 490 & 40 & 450 & $9 \%$ & 0 \\
9 & 39 & 21 & Bill & 490 & 30 & 460 & $7 \%$ & 0 \\
10 & 41 & 23 & Bill & 290 & 20 & 270 & $7 \%$ & 0 \\
11 & 42 & 19 & Bill & 490 & 40 & 450 & $9 \%$ & 0 \\
12 & 44 & 22 & Bill & 350 & 5 & 345 & $1 \%$ & 0 \\
13 & 44 & 21 & Bill & 380 & 30 & 350 & $9 \%$ & 0 \\
14 & 44 & 24 & Bill & 370 & 20 & 350 & $6 \%$ & 0 \\
15 & 46 & 17 & Extended & 480 & 10 & 470 & $2 \%$ & 0 \\
16 & 49 & 22 & Bill & 290 & 30 & 260 & $12 \%$ & 0 \\
17 & 49 & 17 & Bill & 310 & 15 & 295 & $5 \%$ & 0 \\
18 & 52 & 22 & Bill & 390 & 20 & 370 & $5 \%$ & $5 \%$ \\
19 & 55 & 16 & Extended & 310 & 20 & 240 & $8 \%$ & $2 \%$ \\
20 & 61 & 14 & Extended & 400 & 90 & 310 & $29 \%$ & $12 \%$ \\
21 & 62 & 8 & Extended & 370 & 70 & 300 & $23 \%$ & $15 \%$ \\
\hline
\end{tabular}

